\title{
A Novel In Vitro Human Model of Hemangioma
}

Swee T. Tan, M.B.B.S., F.R.A.C.S., Qurratulain Hasan, Ph.D., Marija Velickovic, B.Sc., Beate M. Rüger, M.M.L.Sc., Richard P.F. Davis, Paul F. Davis, Ph.D.

Swee Tan Plastic Surgery Trust (STT) and Department of Medicine, Wellington School of Medicine (QH, $M V, B R, R P F D, P F D)$, Wellington, New Zealand.

Hemangioma, the most common tumor of infancy, is characterized by a proliferation of capillary endothelial cells with multilamination of the basement membrane and accumulation of cellular elements, including mast cells. The initial rapid growth is followed by an inevitable but slow involution. The currently available therapies are empirical and unsatisfactory because what is known of the cellular and molecular basis of hemangioma development is rudimentary. Advances in the understanding of its programmed biologic behavior has been hampered by the lack of a valid human model.

We report here a novel in vitro culture system that is a useful human model of hemangioma. A small fragment of hemangioma biopsy is embedded in fibrin gel in a well of culture plates and incubated in a serum-free, buffered-salt, minimal medium. A complex network of microvessels grows out from the tissue fragments. Biopsies taken from all three phases of hemangioma development were cultured successfully; proliferative phase samples developed microvessels in 1 to 4 days, involuting phase in 5 to 7 days, and involuted phase in 7 to 12 days. The relative growth rates of the microvessels in the culture of biopsies taken from different stages of hemangioma development reflect the growth patterns seen clinically.

This model has been validated using histochemistry, immunohistochemistry, and reverse transcriptase-polymerase chain reaction. Comparison of the number, localization, and phenotype of endothelial and mast cells and the distribution of basement membrane constituents (type IV collagen, perlecan, and laminins) and growth factors (basic fibroblast growth factor, vascular endothelial growth factor, transforming growth factor- $\beta \mathrm{s}$ ) in the biopsy and the tissue after culture shows that

Copyright (C) 2000 by The United States and Canadian Academy of Pathology, Inc.

VOL. 13, NO. 1, P. 92, 2000 Printed in the U.S.A.

Date of acceptance: August 5, 1999.

This work was presented, in part, at the International Society for Study of Vascular Anomalies Workshop, Berlin, Germany, June 27-28, 1998. Address reprint requests to: Swee T. Tan, M.B.B.S., F.R.A.C.S., Swee Tan Plastic Surgery Trust, Bowen Hospital, Churchill Drive, Wellington, New Zealand; e-mail: sweetan@plastsurg.co.nz; fax: 64-4-479-2660. many of the characteristics of the original tissues were retained in culture.

This in vitro human model of hemangioma overcomes some of the deficiencies associated with earlier models. It offers an opportunity for studying the precise cellular, biochemical, and molecular basis of hemangioma. It may also help to elucidate the mechanisms of action of existing therapies and may lead to the identification of novel treatments for hemangioma.

KEY WORDS: Angiogenesis, Culture, Hemangioma, Immunohistochemistry, Reverse transcriptasepolymerase chain reaction.

Mod Pathol 2000;13(1):92-99

Hemangioma, a primary tumor of microvasculature, is characterized by a proliferation of capillary endothelial cells with multilamination of the basement membrane and accumulation of cellular elements, including mast cells, macrophages, plasma cells, and pericytes (1-4). Thirty to $40 \%$ of hemangiomas are first noticed at birth, usually as a pink spot, blanched area, or telangiectasia (4), and exhibit a rapid postnatal growth for 8 to 12 months (proliferative phase), followed by a slow regression for the next 1 to 5 years (involuting phase), with continued improvement in the remaining children until 10 to 12 years (involuted phase) (5). Normal skin is restored in $50 \%$ of patients when involution is complete $(4,6)$. The trigger that initiates hemangioma seems to be a local event, not a hereditary predisposition (7).

Currently available experimental models include the induction of hemangioma in mice by transgenic endothelial cells (8), mouse endothelial cells that have been transformed by polyoma middle $\mathrm{T}$ oncogene $(9,10)$, and endothelial cells obtained from murine and human hemangioma (11). Each of these models has deficiencies; they use animal rather than human cells and tissue, or they involve viral transformation of endothelial cells, which is not known to occur in human hemangioma, or they use a cell culture system that is not influenced by the metabolism of neighboring cells as occurs in 
vivo. Mulliken et al. (12) cultured endothelial cells from human hemangioma on plasma clots. However, the absence of other cellular elements, as well as the necessity of plasma, makes this system less than ideal, especially for investigating the role of modulating molecules. Therefore, none of these systems simulates the cellular and extracellular matrix characteristics of human hemangioma.

We describe here an in vitro tissue culture system that uses human hemangioma specimens that are angiogenically active in a serum-free medium. Using histochemistry, immunohistochemistry, and reverse transcriptase-polymerase chain reaction (RTPCR), we have established that a number of characteristics of hemangioma were retained in the cultured samples.

\section{MATERIALS AND METHODS}

\section{Tissue Samples}

Ten hemangioma biopsies were obtained from nine patients (Table 1) according to a protocol approved by the Wellington Ethics Committee. The specimens were kept moist with normal saline and cleansed of all blood clots with phosphate-buffered saline. Samples from them were snap-frozen in liquid nitrogen for RNA isolation, fixed in formalin for histochemistry and immunohistochemistry, and cultured as described next.

\section{Tissue Culture}

Pieces of fresh operative hemangioma tissue were submerged in serum-free MCDB131 medium (GIBCO BRL, Gaithersburg, MD). Under an operating microscope, the tissue was cut at room temperature into 1-mm explants and embedded in fibrin gel. For the gel, sheep fibrinogen fraction I (Sigma, St. Louis, MO) (3 $\mathrm{mg} / \mathrm{mL})$ was dissolved in MCDB131 medium with streptomycin $(0.1 \mathrm{mg} / \mathrm{mL})$ and penicillin $(100 \mathrm{U} / \mathrm{mL})$, supplemented with $\epsilon$-amino-caproic acid $(0.3 \mathrm{mg} / \mathrm{mL})$ (Sigma) to prevent fibrinolysis. Human plasma thrombin (final concentration $0.5 \mathrm{U} / \mathrm{mL}$ ) (Serva Feinbiochemica, Heidelberg, Germany) was added to the fibrinogen, and $0.7 \mathrm{~mL}$ of the mixture was immediately placed in each well of a culture plate (Nunclon; Nunc Inter Media, Roskilde, Denmark). After gel formation, the tissue explants were placed on top of it. A second aliquot of fibrinogen-thrombin-medium mixture $(0.8 \mathrm{~mL})$ was added so that the tissue fragment was sandwiched between two layers of fibrin gel. After gel formation, $1.5 \mathrm{~mL}$ of the same supplemented MCDB131 medium was added to each well. For each biopsy, 24 well culture plates were used so that multiple analyses with replicates could be carried out. The plates were incubated at $37^{\circ} \mathrm{C}$ in $3 \% \mathrm{CO}_{2} /$ $97 \%$ air in a humidified environment.

The medium was changed every 5 days. After the first passage, some of the cultured tissue samples were placed in Trizol (GIBCO, Life-Technologies) for RNA isolation, and the remainder were fixed in formalin and embedded in paraffin for histochemical and immunohistochemical analyses.

\section{Quantitative Assay of Angiogenesis}

Images of the cultures were captured using a Pixera digital image camera professional system (Digitech, Miami, FL) attached to an inverted microscope (Olympus CK2; Olympus, Tokyo, Japan). The images were taken approximately every 3 days to assess the rate of growth of the neovessels. The neovascular area in each image was outlined and calculated using the program Image $1.62 \mathrm{~b} 7$ software (National Institutes of Health, Bethesda, MD) as described earlier (13). This area is expressed relative to the area of the explant.

\section{Histochemistry}

Three- $\mu$ m-thick sections from the paraffin blocks were attached to poly-L-lysine-coated glass slides (Sigma). Deparaffinized sections were stained with hematoxylin and eosin. Mast cells were detected using Csaba stain as described (14).

TABLE 1. Details of Primary Cultures of Hemangiomas Including Age of Patient at Biopsy, Sex, Site of Lesion, Developmental Phase of Hemangioma, and Time in Culture Before New Vessels Were Detected

\begin{tabular}{|c|c|c|c|c|c|}
\hline Patient & Age & Sex & Site & Phase & First sprouts (days) \\
\hline 1 & 18 days & $\mathrm{F}$ & Perianal & Proliferative & $2-4$ \\
\hline 2 & 3 mo & $\mathrm{F}$ & Axilla & Proliferative $^{a}$ & $1-4$ \\
\hline 3 & $5 \mathrm{mo}$ & $\mathrm{F}$ & Axilla & Proliferative $^{b}$ & $2-4$ \\
\hline 4 & $5 \mathrm{mo}$ & M & Forehead & Proliferative & $3-4$ \\
\hline 5 & $8 \mathrm{mo}$ & $\mathrm{F}$ & Chest & Proliferative & $3-4$ \\
\hline 6 & $13 \mathrm{mo}$ & M & Scalp & Involuting & $5-7$ \\
\hline 7 & $13 \mathrm{mo}$ & $\mathrm{F}$ & Elbow & Involuting & $6-7$ \\
\hline 8 & $5 \mathrm{yr}$ & $\mathrm{F}$ & Upper lip & Involuting & $5-7$ \\
\hline 9 & $6 \mathrm{yr}$ & M & Glabella & Involuted & $7-10$ \\
\hline 10 & $8 \mathrm{yr}$ & $\mathrm{F}$ & Submentum & Involuted & $9-12$ \\
\hline
\end{tabular}

${ }^{a}$ Tissue obtained before intralesional triamcinolone injection.

${ }^{b}$ Tissue obtained 5 weeks after intralesional triamcinolone injection. 


\section{Immunohistochemistry}

Immunohistochemistry was performed as described previously (15-18) with several modifications. Three- $\mu \mathrm{m}$-thick sections were cut, dewaxed, and predigested with protease XXIV (Sigma) $(0.5$ $\mathrm{mg} / \mathrm{mL}$ in $50 \mathrm{~mm} / 1 \mathrm{Tris} \mathrm{HCl} \mathrm{pH} 7.5$, for $10 \mathrm{~min}$ at $37^{\circ}$ C), pronase E (Serva Feinbiochemica) $(0.05 \mathrm{mg} / \mathrm{mL}$ in Tris-buffered saline [TBS], for $10 \mathrm{~min}$ at $37^{\circ} \mathrm{C}$ ), or pepsin (Sigma) $\left(0.01 \mathrm{mg} / \mathrm{mL}\right.$ in $0.1 \mathrm{M} \mathrm{HCl}$ at $37^{\circ} \mathrm{C}$ for $10 \mathrm{~min})$. Endogenous peroxidase was blocked during incubation with secondary (bridging) antibodies (Abs) in $0.5 \%$ casein/TBS by the addition of $1 \%$ D-glucose (BDH, Poole, UK) and 0.85 units/mL glucose oxidase type VIII (Sigma). Dilutions of primary Abs used in the incubations and details of unmasking procedures are given in Table 2. All primary Abs were diluted with TBS/1\% bovine serum albumin, and the sections were incubated overnight at $4^{\circ} \mathrm{C}$. Controls included the omission of primary $\mathrm{Ab}$ and substitution with an irrelevant monoclonal $\mathrm{Ab}$ of the same isotype, or with normal rabbit or goat serum for polyclonal Abs. Mouse monoclonal and rabbit polyclonal Ab binding were detected with a sensitive three-step biotin-streptavidin/immunoperoxidase technique, using biotinylated anti-mouse immunoglobulins (Igs) (BioGenex, San Ramon, CA; 1:50) or biotinylated antirabbit Igs (BioGenex; 1:50) for 30 min followed by incubation with peroxidase-conjugated streptavidin (BioGenex; 1:50) for $30 \mathrm{~min}$ at room temperature. The reactivity of goat polyclonal Abs was revealed using rabbit anti-goat Igs (DAKO; 1:100) as bridging reagents and goat peroxidaseantiperoxidase (DAKO; 1:50), both incubated for 30 mins at room temperature. The sections were exposed to $0.05 \%$ diaminobenzidine in $50 \mathrm{~mm} / \mathrm{l}$ Tris $\mathrm{HCl}, \mathrm{pH} 7.5$, counterstained with hematoxylin, dehydrated, and mounted in DPX (BDH).

\section{Cell Counting}

Mast cells that stained positively for tryptase and chymase were counted at $20 \times$ magnification using a 25-point Zeiss integrating grid. For each section, a minimum of three adjacent fields were counted by each of the two observers (STT and MV).

\section{Reverse Transcriptase-Polymerase Chain Reaction Analysis}

RNA was isolated from the hemangioma biopsy tissues before and after culturing using Trizol reagent (GIBCO). RNA was reverse transcribed to cDNA and amplified using the Perkin Elmer (Norwalk, CT) rTth RT-PCR kit as described (17-21). Briefly, a 10-min RT step was followed by 40 cycles of three-stage PCR using temperatures of $94^{\circ} \mathrm{C}$ for denaturing, $72^{\circ} \mathrm{C}$ for extension, and specific annealing temperatures for each primer set (Table 3 ). The amplified products were electrophoresed on $2 \%$ agarose gel in Tris-acetic acid- EDTA buffer. The quality of the amplifiable RNA was established using hypoxanthine phosphoribosyl transferase as the control gene. The other genes studied were for the cytokines basic fibroblast growth factor (bFGF) and transforming growth factor- $\beta$ s (TGF- $\beta 1,-\beta 2$, and $-\beta 3$ ). All of the primers used (Table 3 ) were designed using the Oligo Program based on published human sequences and were synthesised by Operon Technologies (Alameda, CA).

\section{RESULTS}

\section{In Vitro Hemangioma Culture}

For the in vitro culture, biopsy tissues from five hemangiomas in the proliferative (Fig. 1A), three in the involuting (Fig. 1B), and two in the involuted (Fig. 1C) phases were used. Histology of each of these phases is shown in Figures 1D-F. Each fragment of the hemangioma tissues in culture gave rise to a complex array of microvessels emanating from its perimeter (Fig. 2). The outgrowths stained positively with Von Willebrand factor (Fig. 3), confirming the presence of endothelial cells.

TABLE 2. Antibodies and Unmasking Procedures for Immunohistochemistry

\begin{tabular}{|c|c|c|c|c|}
\hline Marker & Primary antibody & $\begin{array}{l}\text { Staining } \\
\text { dilutions }\end{array}$ & $\begin{array}{l}\text { Unmasking } \\
\text { procedure }\end{array}$ & Source of primary antibody \\
\hline Perlecan & Mouse mAb clone MAB458 & $1: 25$ & Protease & Chemicon, Temecula, CA \\
\hline Collagen IV & Goat pAb & $1: 400$ & Pronase E & Southern Biotechology, Birmingham, AL \\
\hline Laminin $\alpha 1$ chain & Mouse mAb clone $4 \mathrm{C} 7$ & $1: 100$ & Protease & Gibco BRL, Gaithersburg, MD \\
\hline Laminin $\alpha 2$ chain & Mouse mAb clone $5 \mathrm{H} 2$ & $1: 200$ & Protease & Gibco BRL, Gaithersburg, MD \\
\hline Laminin $\beta 1$ chain & Mouse mAb clone $4 \mathrm{E} 10$ & $1: 200$ & Protease & $\begin{array}{l}\text { Developmental Studies, Hybridoma Bank, } \\
\text { Iowa City, IA }\end{array}$ \\
\hline Laminin $\beta 2$ chain & Mouse mAb clone C4 & $1: 3000$ & Protease & Gibco BRL, Gaithersburg, MD \\
\hline Laminin $\gamma 1$ chain & Mouse mAb clone $2 \mathrm{E} 8$ & $1: 200$ & Protease & Gibco BRL, Gaithersburg, MD \\
\hline vWf & Rabbit Ab & $1: 8000$ & Pepsin & Dako Corp., Carpinteria, CA \\
\hline CD31 & Mouse mAb clone JC/70A & $1: 25$ & Pronase & Dako Corp., Carpinteria, CA \\
\hline Mast cell tryptase & Mouse mAb clone AA1 & $1: 1000$ & Pronase E & Dako Corp., Carpinteria, CA \\
\hline Mast cell chymase & Mouse mAb clone MAB1254 & $1: 200$ & Pronase E & Chemicon, Temecula, CA \\
\hline VEGF & Goat pAb clone & $1: 30$ & - & R\&D Systems, Minneapolis, MN \\
\hline$b \mathrm{FGF}$ & Rabbit pAb & $1: 40$ & - & Santa Cruz Biotech, Santa Cruz, CA \\
\hline
\end{tabular}




\begin{tabular}{|c|c|c|c|}
\hline Gene & Primers (sense and antisense) & Annealing temperature & Reference no. \\
\hline \multirow[t]{2}{*}{ HPRT } & 5'CCTTTGGGCGGATTGTTGT3' & $52^{\circ} \mathrm{C}$ & 17,20 \\
\hline & 5'TTTTTTTTTTTTTTAAATTTTTGGGAAT3' & & \\
\hline \multirow[t]{2}{*}{ TGF- $\beta 1$} & 5'GGAAACCCACAACGAAATCTATGAC3' & $56^{\circ} \mathrm{C}$ & 21 \\
\hline & 5'TTCCCCTCCACGGCTCAAC3' & & \\
\hline \multirow[t]{2}{*}{ TGF- $\beta 2$} & 5'GCGAGAGGAGCGACGAAGAG3' & $56^{\circ} \mathrm{C}$ & 21 \\
\hline & 5'AGCCTGGGTTGGAGATGTTA3' & & \\
\hline \multirow[t]{2}{*}{ TGF- $\beta 3$} & 5'CTGGCGGAGCACAACGAACT3' & $56^{\circ} \mathrm{C}$ & 21 \\
\hline & 5'GGACTCTCTTCTCAACAGCCACTCAC3' & & \\
\hline \multirow[t]{2}{*}{$b \mathrm{FGF}$} & 5'AGCGACCCTCACATCAAGC3' & $60^{\circ} \mathrm{C}$ & 19 \\
\hline & 5'AAAAGAAACACTCATCCGTAACACA3' & & \\
\hline
\end{tabular}

HPRT, hypoxanthine phosphoribosyl transferase; TGF, transforming growth factor; $b$ FGF, basic fibroblast growth factor.

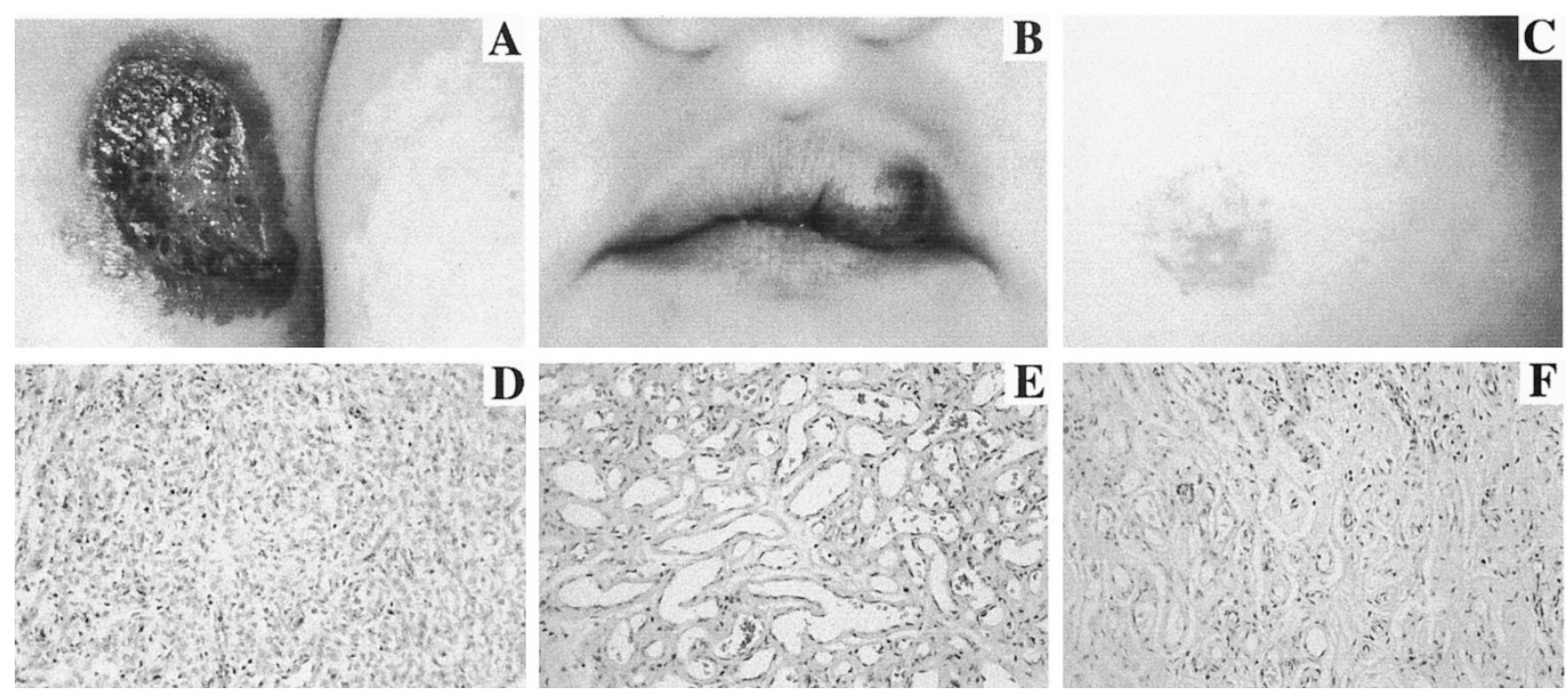

FIGURE 1. Hemangioma at different phases of development. A, an ulcerated proliferative hemangioma in the perianal region of an 18-day-old infant. B, an involuting hemangioma on the upper lip of a 5-year-old girl. C, an involuted hemangioma in the submental region of an 8-year-old girl. D-F, hematoxylin and eosin staining of sections from biopsies from A, B, and C, respectively (original magnification, 357 $\times$ ).
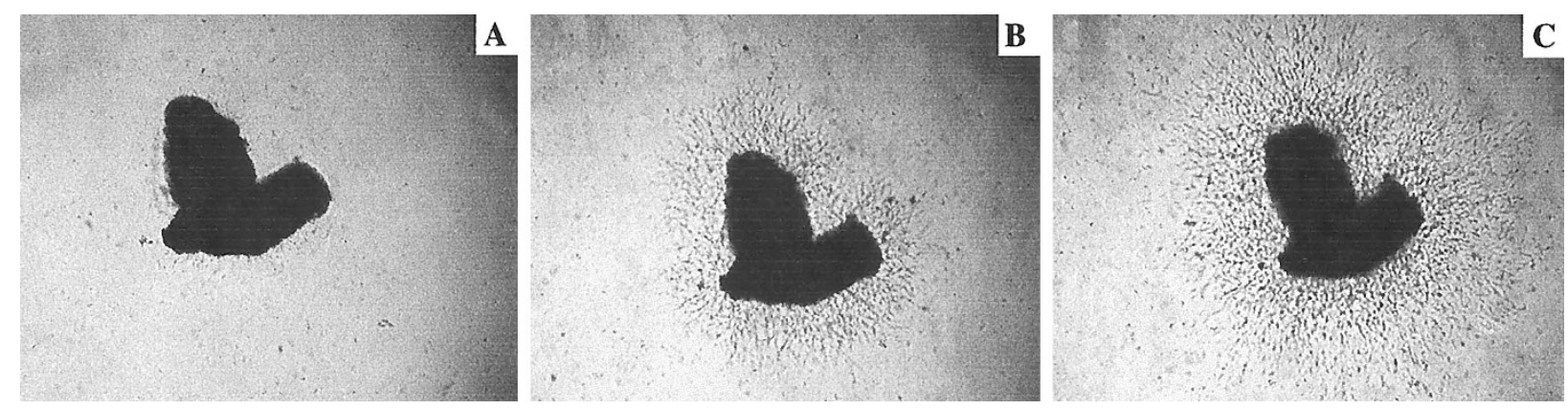

FIGURE 2. Human hemangioma in culture. Tissue taken from a proliferative hemangioma embedded in fibrin gel and cultured, as described in Materials and Methods, at 2 days $(\mathbf{A})$, at 4 days $(\mathbf{B})$, and at 6 days in culture (C) (original magnification, 22.5×).

\section{Quantitation of the In Vitro Hemangioma Angiogenesis}

The extent of the vessel outgrowths was quantified by digital image analysis. Tissue samples cultured from proliferative phase lesions were found to give rise to microvessels within 1 to 4 days in culture. The first sprouts of microvessels were seen between 5 and 7 days when tissue was taken during involuting phase, whereas involuted biopsy tissues took 7 to 12 days to grow new microvessels. Relative growth rates are shown in Figure 4.

\section{Phenotypic Features of Hemangioma Tissue after Culture}

Examination by histochemistry and immunohistochemistry of the expression of a number of cellular components, matrix proteins, and growth factors previously described for hemangioma $(5,22)$ showed that these phenotypic characteristics were retained in culture. RT-PCR also demonstrated that the transcripts for the growth factors studied were present in both the biopsies and the tissues after culture. 


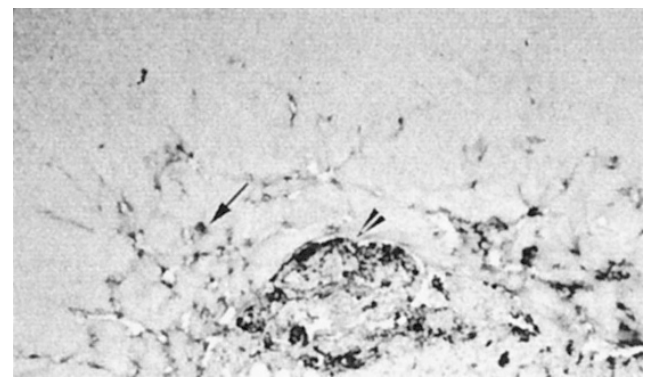

FIGURE 3. Section of a representative hemangioma culture. Positive staining for Von Willebrand factor is localized to the neovessels of the biopsy (arrow) and tissue of the culture (arrow head). (Original magnification, $43 \times$ )

Immunohistochemical staining of the biopsy and the tissue after culture with anti-CD31 (Figs. 5A, B) and anti-Von Willebrand factor (data not shown) showed a similar distribution that was localized to endothelial cells. Csaba stain showed that in both the biopsies and the explants, mast cells were present and expressed the biogenic amine phenotype (data not shown) in all three phases. The distribution of tryptase-positive mast cells was also similar (Figs. 5C, D). There was no significant quantitative difference in the number of tryptasepositive mast cells in the original biopsy and tissue after culture. (Proliferative: tissue: mean $=33.60 \pm$ 2.10 [SEM] $[n=10$ fields]; culture: $34.00 \pm 2.01$ [SEM] [ $n=6$ fields]; N.S. Involuting: tissue: mean $=$ $50.83 \pm 2.55$ [SEM] [ $n=12$ fields]; culture: $46.17 \pm$ 4.47 [ $n=6$ fields], N.S.). In both the original and the tissue after culture, the $\alpha-1$ chain of type IV collagen (Figs. 5E, F), $\beta 2$ (Figs. 5G, H), $\alpha 1$ and $\gamma 1$ chains (data not shown) of laminin, and perlecan (Figs. 5I, J) were detected in the basement membrane. The $\alpha 2$, $\beta 1$, and $\gamma 2$ chains of laminin were not present (data not shown) in either biopsy or tissue after culture. $b$ FGF (Figs. $5 \mathrm{~K}, \mathrm{~L}$ ) and vascular endothelial growth factor (data not shown) localized predominantly to the endothelial and mast cells in both the biopsy and the tissue after culture.

\section{Reverse Transcriptase-Polymerase Chain Reaction Analysis}

Total RNA isolated from the biopsy and the sample after culturing was of good quality and was amplifiable. Figure 6 shows the constitutively expressed hypoxanthine phosphoribosyl transferase gene transcripts from the hemangioma samples before and after culture. Transcripts of cytokines TGF$\beta 1,-\beta 2$, and $-\beta 3$ and $b$ FGF identified in biopsies were also present in the tissue after culture (Fig. 6).

\section{DISCUSSION}

Hemangioma offers a unique model to study angiogenesis as a primary tumor of microvasculature in which angiogenesis is initially excessive, followed by inhibition and regression of the newly formed blood vessels (23). The cellular and biochemical events that initiate and regulate its proliferation and natural regression are unknown. Rudimentary knowledge of the pathogenesis of hemangioma has led to empirical and unsatisfactory therapies (2224). Identification of the molecular trigger for hemangioma is of great interest both clinically and biologically. Presumably, the triggering event involves a potent stimulator of angiogenesis (7). Identification of the molecules involved may provide information that could be used for controlling common infantile hemangioma and angiogenesis. In the present study, a model that mimics as closely as possible the features of the hemangioma was developed.

Each of the models currently available to study hemangioma has deficiencies. For example, in the transgenic mouse models, a "hemangioma" develops after introduction of virally transformed endothelial cells $(8-10)$. The natural history of these tumors, which often undergo malignant transformation and grow throughout life, is very different from human hemangiomas (7). Furthermore, the relevance of this oncogene incorporation to the development of human hemangioma has not been established, because there is no evidence that human lesions contain transformed endothelial cells. In another model, mice expressing Fps/Fes proteintyrosine kinase transgene with an activating mutation have multiple hemangioma-like tumors at specific sites (25). However, these tumors never regress, and the mice die of internal hemorrhage. Hence, the value and validity of such models are questionable. Similarly, endothelial cells derived from murine (11) and human $(11,12)$ hemangioma and grown as pure cultures are devoid of the other cells and associated extracellular matrix that normally are present in vivo. Therefore, these cellular elements' and matrix constituents' influence on and interaction with the endothelial cells cannot be determined.

In this article, we describe a human in vitro model of hemangioma that overcomes some of the deficiencies associated with other previously described systems. Unlike many of the models, our culture system uses human hemangioma biopsies. Thus, any disadvantages arising from the use of animal models is eliminated. Consequently, the cellular and molecular mechanisms involved in this culture system would more likely mimic the in vivo situation. Another advantage is the ability of the neovessels to grow from the tissue sections in the absence of exogenous serum. Neovascularization in a minimal medium allows agents such as growth factors and antibodies to be added so that their 


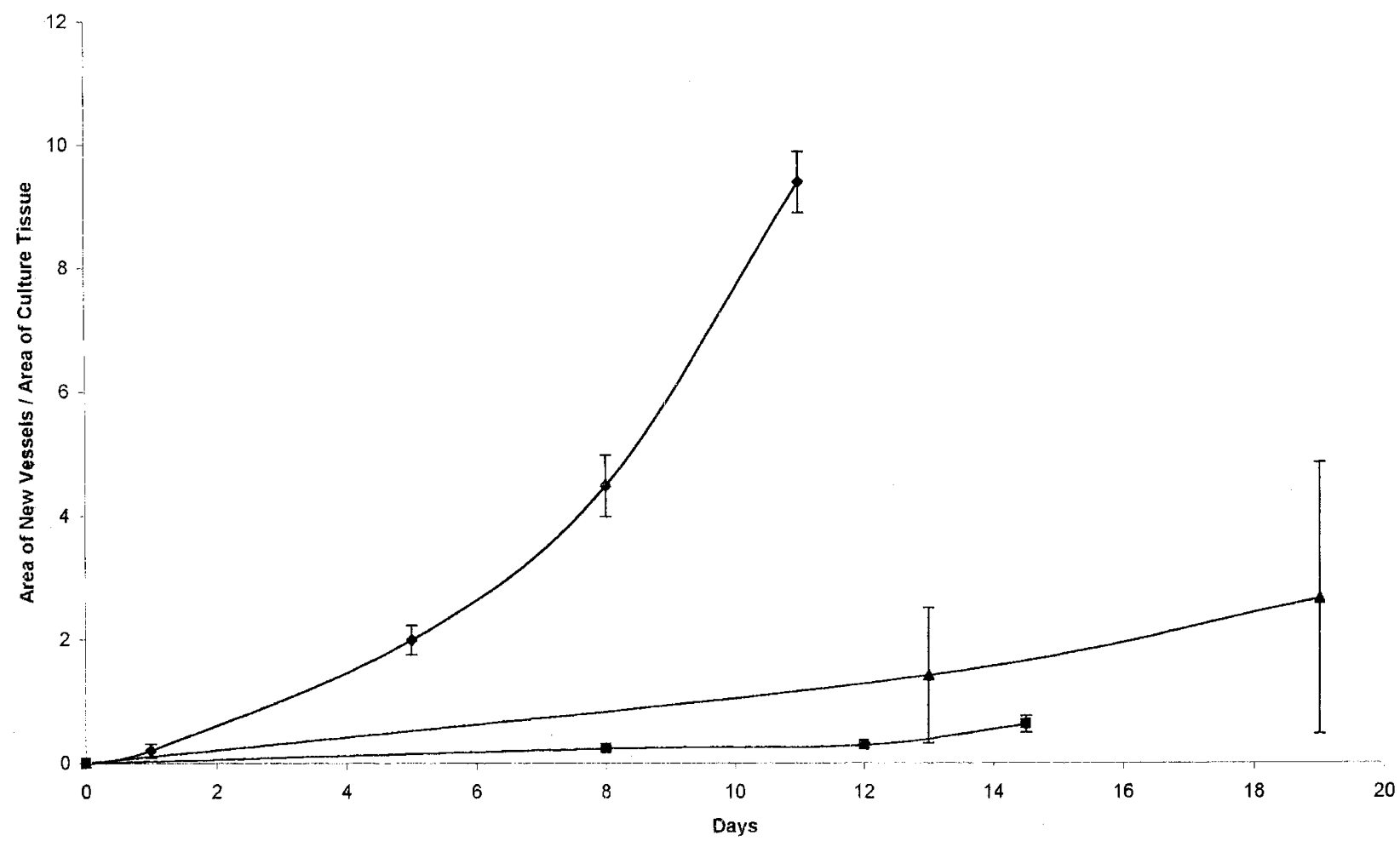

FIGURE 4. The relative growth rates of microvessels from hemangioma tissue in culture. The ratio of the area occupied by new vessels to the area of hemangioma tissue section from which they emanate. $\bullet-\downarrow$, proliferative; $\boldsymbol{\Delta}-\boldsymbol{\Delta}$, involuting; $\mathbf{\square} \mathbf{\square}$, involuted. These areas were measured at several time points as described in Materials and Methods. Each value is the mean of 3 to 5 wells. Error bars represent standard deviation.

effect can be studied without the interaction or influence of serum constituents.

The more in vivo features of a lesion that can be maintained in a model system, the more valid the imitation is. In our model, both endothelial and mast cells that are characteristic of hemangioma (1-5) maintain similar phenotype and number in the tissue after culture. The basement membrane constituents of the cultured section show a similar distribution to that of the biopsy specimens. Of particular note is the retention of the $\beta 2$ laminin chain that is characteristic of vascular basal lamina. Expression of growth factors (e.g., vascular endothelial growth factor, $b$ FGF, TGF- $\beta$ s) known to be relevant to angiogenesis is retained in culture and is demonstrated both transcriptionally and translationally. These growth factors have been demonstrated to be major promoters of angiogenesis in general and of hemangiomas in particular $(5,22$, 26-29). Their presence in this model attests to the validity of this culture system for investigating the mechanism involved in hemangioma proliferation and involution. Further support for the utility of the system is provided by the observation that an angiogenic response occurs with biopsies taken at any phase of hemangioma development. The slower rates of neovascularization in biopsies obtained at involuting and involuted phases compared with those from the proliferative phase provide further evidence that the in vivo phenotype is maintained in culture. Furthermore, cultures can be maintained through several passages, allowing the growth of microvessels to be observed for several weeks. However, a section of the original tissue is necessary for the maintenance of repeated cultures, which suggests that factors from within the hemangioma tissues are essential for the maintenance of angiogenesis (Tan ST, Velickovic M, Davis PF, unpublished observations).

Although there are features of this model to be confirmed, it does demonstrate several properties that have been observed in similar models based on aortic rings (30) and human placental vessels (31) cultured in fibrin gels. Thus, it is likely that the role of modulators that have been shown to be effective in these other systems can be investigated in this pathologic lesion using the model described. This model offers opportunities to elucidate mechanisms regulating the programmed biologic behavior of hemangioma. It also provides a means to study the mechanisms of various existing and experimental pharmacologic therapies such as steroids and interferon- $\alpha$. As well it may assist in identifying novel chemotypes for the treatment of hemangioma.

Acknowledgments: This work was supported by grants from the Reconstructive Plastic Surgery Research Foundation, the University of Otago, the 

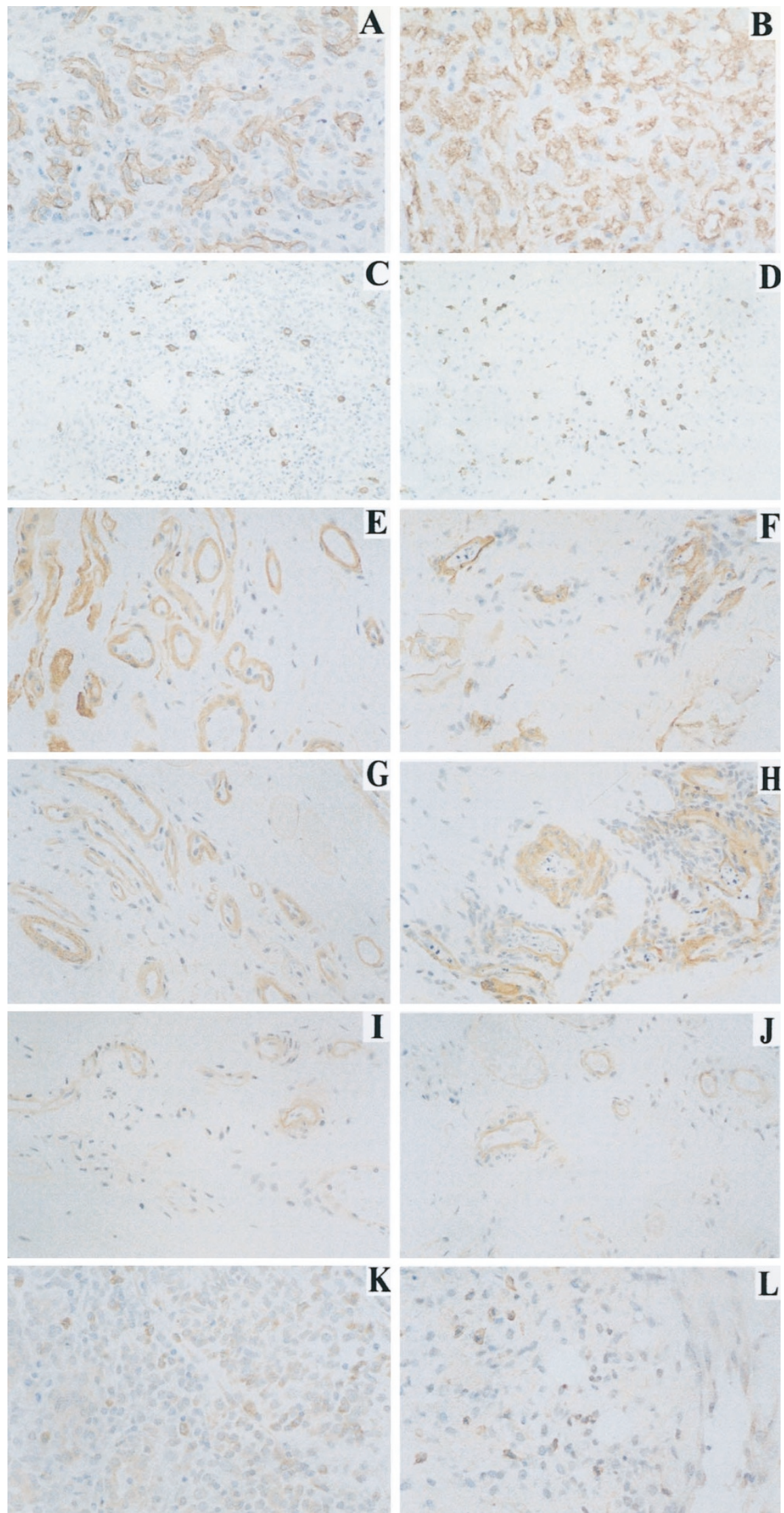

FIGURE 5. Immunohistochemical localization of constituents in hemangioma biopsy tissues (A, C, E, G, I, K) compared with the tissues after culture (B, D, F, H, J, L). Hemangioma tissues from proliferative phase: A-D, K, and L; involuting phase: E-J. A and B: anti-CD31; C and D: mast cell tryptase; $\mathbf{E}$ and $\mathbf{F}$ : anti $\alpha$ l-chain type IV collagen; $\mathbf{G}$ and $\mathbf{H}$ : laminin $\beta 2$ chain; $\mathbf{I}$ and $\mathbf{~ J}$ : perlecan; $\mathbf{K}$ and $\mathbf{L}$ : basic fibroblast growth factor. (Original magnification, $185 \times)$. 


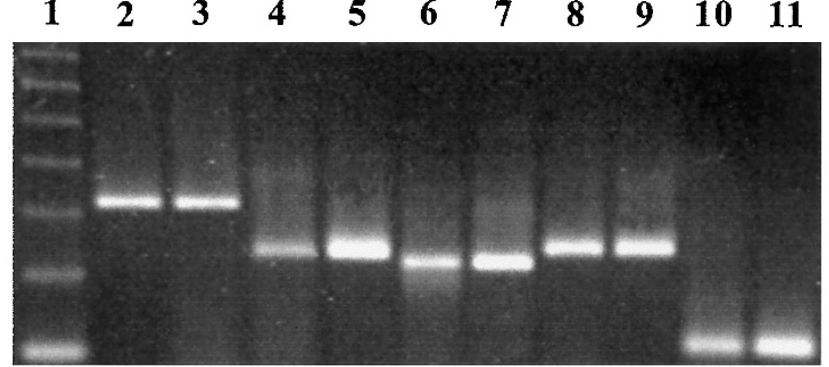

FIGURE 6. Ethidium bromide stained $2 \%$ agarose gel showing reverse transcriptase-polymerase chain reaction products in biopsy (lanes 2, 4, 6,8 , and 10) and tissue after culture (lanes 3, 5, 7, 9, and 11), taken from a proliferative hemangioma. Lane 1 is the $123 b p$ DNA ladder; lanes 2 and 3: hypoxanthine phosphoribosyl transferase $(\sim 395 \mathrm{bp})$; lanes 4 and 5: transforming growth factor (TGF)- $\beta 3(\sim 312 b p)$; lanes 6 and 7 : TGF- $\beta 1(\sim 301 b p)$; lanes 8 and 9: TGF- $\beta 2(\sim 363 b p)$; lanes 10 and 11 : basic fibroblast growth factor $(\sim 145 \mathrm{bp})$.

Wellington Medical Research Foundation, Lottery Health Research, and the Health Research Council of New Zealand. We are grateful to C. Marstella for her assistance with the preparation of this manuscript.

\section{REFERENCES}

1. Mulliken JB, Glowacki J. Hemangiomas and vascular malformations in infants and children: a classification based on endothelial characteristics. Plast Reconstr Surg 1982;69:41222.

2. Glowacki J, Mulliken JB. Mast cells in hemangiomas and vascular malformations. Pediatrics 1982;70:48-51.

3. Dethlefsen SM, Mulliken JB, Glowacki J. An ultrastructural study of mast cell interactions in hemangiomas. Ultrastruct Pathol 1986;10:175-83.

4. Mulliken JB. Diagnosis and natural history of haemangiomas. In: Mulliken JB, Young AE, editors. Vascular birthmarks: haemangiomas and vascular malformations. Philadelphia: W.B. Saunders; 1988. pp. 41-62.

5. Takahashi K, Mulliken JB, Kozakewich HPW, Rogers RA, Folkman J, Ezekowitz RAB. Cellular markers that distinguish the phases of hemangioma during infancy and childhood. J Clin Invest 1994;93:2357-64.

6. Enjolras O, Mulliken JB. The current management of vascular birthmarks. Pediatr Dermatol 1993;10:311-3.

7. Vikkula M, Boon LM, Mulliken JB, Olsen BR. Molecular basis of vascular anomalies. Trends Cardiovasc Med 1998;8:28192.

8. Dubois-Stringfellow N, Kolpack-Martindale L, Bautch VL, Azizkhan RG. Mice with hemangiomas induced by transgenic endothelial cells: a model for the Kasabach-Meritt syndrome. Am J Pathol 1994;144:796-806.

9. Williams RL, Risau W, Zerwes H-G, Drexler H, Aguzzi A, Wagner EF. Endothelioma cells expressing the polyoma middle $\mathrm{T}$ oncogene induce hemangiomas by host cell recruitment. Cell 1989;57:1053-63.

10. Sage EH. Secretion of SPARC by endothelial cells transformed by polyoma middle $\mathrm{T}$ oncogene inhibits the growth of normal endothelial cells in vitro. Biochem Cell Biol 1992; 70:579-92.

11. Meninger CJ, Brightman SE, Kelly KA, Zetter BR. Increased stem cell factor release by hemangioma-derived endothelial cells. Lab Invest 1995;72:166-73.
12. Mulliken JB, Zetter BR, Folkman J. In vitro characteristics of endothelium from hemangiomas and vascular malformations. Surgery 1982;92:348-53.

13. Davis PF, He Y, Furneaux RH, Johnston PS, Rüger BM, Slim GC. Inhibition of angiogenesis by oral ingestion of powdered shark cartilage in a rat model. Microvasc Res 1997;54:17882.

14. Strobel S, Miller HRP, Ferguson A. Human intestinal mucosal mast cells: evaluation of fixation and staining techniques. J Clin Pathol 1981;34:851-8.

15. Rüger B, Dunbar PR, Hasan Q, Sawada H, Kittelberger R, Greenhill N, et al. Human mast cells produce type VIII collagen in vivo. Int J Exp Pathol 1994;75:397-404.

16. Neale TJ, Rüger BM, Macuaulay HA, Dunbar PR, Hasan Q, Bourke A, et al. Tumour necrosis factor- $\alpha$ is expressed by glomerular visceral epithelial cells in human membranous nephropathy. Am J Pathol 1995;146:1444-54.

17. Rüger BM, Hasan Q, Greenhill NS, Davis PF, Dunbar PR, Neale TJ. Mast cells and type VIII collagen in human diabetic nephropathy. Diabetologia 1996;39:1215-22.

18. Rüger BM, Hasan Q, Erb KJ, Davis PF. Progression of renal disease in interleukin-4 transgenic mice: involvement of transforming growth factor- $\beta$. Int J Exp Pathol 1999;80:11323.

19. Hasan Q, Rüger BM, Davis PF, Greenhill NS, MurrayMcIntosh RP, Dunbar R, Neale TJ. Analysis of expression of multiple cytokines in individual human renal biopsies. Kidney Inter 1997;51:1311-2.

20. Bird SD, Hasan Q, Davis PF, Walker RJ. Platelet derived growth factor-BB induced calcium transient in cultured human peritoneal mesothelial cells. ASAIO Journal 1998;44: 835-40.

21. Hasan Q, Dunbar PR, Murray-McIntosh RP, Neale TJ. Transforming growth factor $\beta$ isoforms in human glomerulonephropathies. Nephrology 1998;4:353-9.

22. Tan ST, Velickovic M, Rüger BM, Davis PF. Cellular and extracellular markers of hemangioma. Plast Reconstr Surg. In press.

23. Mulliken JB, Boon LM, Takahashi K, Ohlms LA, Folkman J, Ezekowitz AB. Pharmacologic therapy for endangering hemangiomas. Current Opinion in Dermatol 1995;109-13.

24. Hasan Q, Tan ST, Gush J, Peters S, Davis PF. Steroid therapy of a proliferating hemangioma: Histochemical and molecular changes. Pediatrics. In press.

25. Greer P, Haigh J, Mbamalu G, Khoo W, Bernstein A, Pawson T. The Fps/Fes protein-tyrosine kinase promotes angiogenesis in transgenic mice. Mol Cell Biol 1994;14:6755-63.

26. Pepper MS, Ferrara N, Orci L, Montesano R. Potent synergism between vascular endothelial growth factor and basic fibroblast growth factor in the induction of angiogenesis in vitro. Biochem Biophys Res Comm 1992;189:824-31.

27. Folkman J, D'Amore PA. Blood vessel formation: what is its molecular basis? Cell 1996;87:1153-5.

28. Jang Y-C, Arumugam S, Ferguson M, Gibran NS, Isik FF. Changes in matrix composition of human hemangiomas. J Surg Res 1998;80:9-15.

29. Chang J, Most D, Bresnick S, Mehrara B, Steinbrech DS, Reinisch J, et al. Proliferative hemangiomas: analysis of cytokine gene expression and angiogenesis. Plast Reconstr Surg 1999;103:1-9.

30. Nicosia RF, Ottinetti A. Growth of microvessels in serum-free matrix culture of rat aorta: a quantitative assay of angiogenesis in vitro. Lab Invest 1990;63:115-22.

31. Brown KJ, Maynes SF, Bezos A, Maguire DJ, Ford MD, Parish CR. A novel in vitro assay for human angiogenesis. Lab Invest 1996;75:539-54. 